\title{
探究无人机遥感技术在地质灾害调查中的应用
}

\section{Exploring the Application of UAV Remote Sensing Technology in Geological Hazard Survey 陈莉莉}

\author{
Lili Chen
}

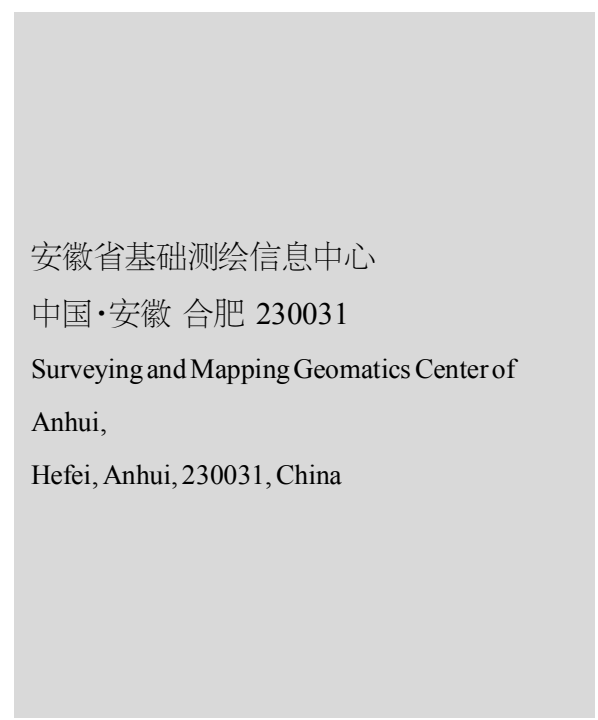

【摘 要】在科学技术水平快速提升的大背景下, 无人机遥感技术作为一种新兴技术, 在很 多领域得到了广泛应用, 尤其在现代化社会的发展中, 在地质灾害调查中得到了广泛应用, 在很大程度上提升了地质灾害防治工作的整体质量。因此, 测绘部门需要注重无人机遥感 技术在地质灾害调查中的应用。

【Abstract】In the background of rapid improvement of science and technology, UAV remote sensing technology as a new technology has been widely used in many fields, especially in the development of modern society, in geological disaster investigation, which has greatly improved the overall quality of geological disaster prevention and control. Therefore, the surveying and mapping department needs to pay attention to the application of UAV Remote Sensing Technology in geological disaster investigation.

【关键词】无人机遥感技术; 地质灾害调查; 应用

【Keywords \UAV remote sensing technology; geological hazard survey; application 【DOI】10.36012/se.v2i1.1178

\section{1 引言}

在现代化地质灾害监测过程中, 无人机遥感技术发挥着 重要作用, 在很多行业中得到了有效应用, 凸显了无人机遥感 技术的重要性, 尤其在地质灾害监测中的应用, 为社会的生产 和生活做出了更大贡献, 有助于预防和分析地质灾害, 为人民 群众的生命财产安全提供保障。在未来地质灾害监测工作中, 无人机遥感技术将得到快速发展。基于此, 本文分析了无人机 遥感技术在地质灾害调查中的应用, 分析了无人机遥感技术 在地质灾害调查中的应用策略。

\section{2 无人机遥感技术在地质灾害调查中的应用}

\section{1 工程实例}

某峡谷工程项目位于皖南山区的景区内, 地形地貌具有 一定的复杂性, 地表结构破碎, 地处低纬度高海拔区域, 景区 海拔一般是 1350 1650m, 峡谷顶部海拔是 $1416 \mathrm{~m}$, 最低海拔 是 $1130 \mathrm{~m}$, 相对高差是 $286 \mathrm{~m}$, 景区内部植被覆盖率比较好, 已 达到 50\%, 在危岩体分布立面中, 构成间距 10 30m 的岩土植 被分层。

\section{2 应用实践}

\subsection{1 快速测绘}

在地质测绘过程中, 无人机遥感技术能够被应用到任何 时候、任何地点, 这项技术不受各方面因素的制约, 相关技术 人员可以在地震多发区域, 利用无人机遥感技术完成监测和 测绘工作 ${ }^{[1]}$ 。测绘技术人员利用无人机遥感技术精准预测、拍 摄分析功能, 针对地质灾害多发区域进行全天候监测, 并对灾 害区域的地质层稳定情况进行分析, 针对将要发生、未发生的 事件做好预防和准备工作。无人机遥感技术在地质灾害监测 过程中的应用, 有助于工作人员及时地根据其中的变动进行 控制, 避免出现无法及时达到事件发生区域的问题, 提高地质 测绘的整体效率和质量。另外,无人机遥感技术的拍摄功能比 较清晰, 在某些区域出现地质灾害的情况下, 不会对无人机遥 感技术实时分析和监控地质灾害情况带来不利影响，无人机 遥感技术在发现不正常情况时，可以利用终端遥控无人机在 同一区域不同层面进行拍摄，并深入分析各个层面的实际情 况, 及时、准确地掌握地质灾害区域的信息, 并对其进行有效 调整, 针对地质灾害区域进行施救。 
测绘技术 Surveying and Mapping Technique

\section{2 .2 排查测评}

无人机遥感技术能够针对不同层面的同一地区进行多角 度拍摄, 做好拍摄照片数据分析工作, 以获取全面、准确的事 发现场状况,无人机遥感技术还可以二次分析地质情况, 在出 现地质灾害问题时, 无人机遥感技术可以预测下次灾害, 及时 排查受伤人员,合理地划分不稳定区域,为救援工作的顺利开 展提供帮助。另外,在未发生地质灾害的区域,无人机遥感技 术监测到危险问题、分析不稳定地壳运动的情况下, 需要及时 地调整这一区域的实际情况, 在无法避免地质灾害时, 需要及 时地疏散人群, 将灾害损失度、伤害程度降至最低。

\section{2 .3 地质灾害应急处理}

针对易发生地质灾害的区域、已发生地质灾害的区域,无 人机可以全面分析这些区域的地质灾害情况，如适合躲避的 区域极易引发二次伤害，甚至可以测量地质灾害区域的天气 情况、大气状况。无人机遥感技术不受时间、空间等各项条件 的局限性影响,多角度、全方位分析并处理地质灾害区域的照 片, 通过对其进行数据整理, 传输到终端设备中, 成为地质灾 害区域和外界联系的媒介。除此之外,救援工作一般不是在白 天完成，如地质灾害破坏线路导致灾害区域的正常用电带来 很大影响, 而救援工作很难在夜间进行。但是, 无人机遥感技 术的应用不会被各项恶劣天气所影响，无人机遥感技术也会 将精准数据传输到终端设备中, 由测绘人员传输给施救人员, 为夜间展开救援工作提供了很大便利。

\section{2 .4 获取数据}

测绘技术人员在野外实地调查复核的过程中，初步判定 出危岩体在大气降雨、气温等风化营力的作用下,软弱夹层变 形模量不断降低, 形成了贯通的构造节理和风化卸荷裂陌, 岩 体结构面的变形模量日益降低,逐层剥离,在坡面中形成了以 层面、夹层为底界的突出危岩体, 进而出现倾倒-崩落的失稳 模式。无人机遥感技术体积小、重量轻、地面操作可视化, 能避 开传统方法所带来的种种弊端，因而可获取更精细化、准确 化、信息化的影像数据。在无人机航空摄影测量技术数据采集 过程中, 测绘技术人员主要依托于 Map Matrix 全数字摄影测 量系统, 获取更多准确的数据, 为崩塌危岩体评价的稳定性提 供保障。这一系统的自动化程度较高, 且可以有效保障数据编 人及处理的精确程度。此过程的核心在于构建立体化模型、完 成数字线划图及正射影像, 以满足地质灾害调查的基本要求 ${ }^{[2]}$ 。

\section{3 无人机遥感技术在地质灾害调查中的 应用策略}

\section{1 加大无人机遥感技术的研究力度}

与传统的航拍技术相比，无人机遥感技术在地质灾害监
测过程中的精确度、灵活性和稳定性具有很大优势。在现代化 社会的发展中, 相关人员需要加大无人机遥感技术研究力度, 进一步提升无人机拍摄的整体频率，使其在不良天气测绘过 程中提高测绘的整体精度，拓展无人机遥感技术的发展空间。 另外, 相关部门需要优化无人机主机的硬件设备, 引进轻巧的 无人机主机, 携带更多高科技设备, 大力开创实际意义的新功 能。在新时期的快速发展中, 中国无人机遥感技术仍处于初级 发展阶段, 尤其是数据信息保护工作还不够完善, 在无人机遥 感技术的发展中, 极易引发数据盗窃问题, 威胁着无人机传感 信号事件的出现。另外, 软件开发还可以朝向抗干扰能力以及 数据加密方面进行, 保障无人机传输数据的安全性。

\section{2 培养高素质的测绘人员}

在新时期测绘行业的发展中, 测绘工作的实施需要先进 技术作为支持, 不仅对无人机自身提出了更高要求, 还需要无 人机操作技术人员提高自身的综合素质。为了培养更多复合 型优秀人才, 测绘部门需要加强对测绘技术人员的培训和教 育, 使其实时了解地质灾害现场的实际情况, 掌握地质灾害相 关知识, 这样无人机操作人员才能够更加了解数据处理和遥 感技术的相关内容。除此之外, 测绘企业需要建立高素质的测 绘队伍, 操作技术人员需要准确地判断各项突发事故, 并实行 科学、合理的应对措施 ${ }^{[3]}$ 。因此, 在现代化社会的发展中, 无人 机操作技术人员需要学习更多无人机相关的知识, 注重自身 素质的培养,进一步丰富技术人员自身的知识。

\section{4 结语}

综上所述, 在新时期的社会发展中, 无人机遥感处于探索 和发展时期, 需要投入更多的设备成本作为支持, 这就对操作 和数据处理专业化能力提出了更高的要求, 但无人机遥感技 术在地质灾害勘查中, 尤其是山势险峻区域比较少见。同时, 在地质灾害勘察过程中, 无人机遥感技术应用中遇到很多问 题, 如技术门槛高、法律法规和技术标准不完善等, 相关部门 需要注重这些问题,并实行相应的措施和政策予以优化。

\section{参考文献}

[1]何东升.无人机遥感技术在地质灾害监测中的应用 [J].城市建 设理论研究(电子版),2019(11):77.

[2]翟代廷.无人机遥感技术在地质灾害监测中的应用 $[\mathrm{J}]$. 世界有 色金属,2018(17):279.

[3] 赵淑玲,王泽,王晓娜.无人机遥感技术在地质灾害监测中的应 用分析[J].中小企业管理与科技(上旬刊),2018(5):167-168. 